\title{
A role for Dimethylarginine Dimethylaminohydrolase 1 (DDAH1) in mammalian development
}

\author{
ROSS A. BRECKENRIDGE*,1,2, PETER KELLY¹, MANASI NANDI ${ }^{1}$, PATRICK J. VALLANCE1,\#, \\ TIMOTHY J.MOHUN ${ }^{2}$ and JAMES LEIPER ${ }^{1}$ \\ ${ }^{1}$ Centre for Clinical Pharmacology, University College London, BHF Laboratories, London and \\ ${ }^{2}$ MRC National Institute for Medical Research, London, UK
}

\begin{abstract}
Nitric oxide has been linked to a number of embryonic processes, yet the role of nitric oxide signalling in development remains largely unknown. Dimethylarginine Dimethylaminohydrolase 1 and 2 (DDAH1/2) catalyse the breakdown of asymmetric dimethylarginine, an endogenous inhibitor of nitric oxide production, and may also have nitric oxide-independent functions. We have generated transgenic mice targeting the DDAH1 and DDAH2 loci. Here we report that homozygous DDAH1 null embryos are generated at low frequency, and do not progress through embryonic development. During normal development $D D A H 1$ RNA is expressed in the left ventricle, cardiac outflow tract and developing vasculature. In contrast, DDAH2 homozygous null mice are viable and fertile, with a normal lifespan. DDAH2 expression is seen in the developing left ventricle and cardiac outflow tract, and additionally in the peripheral nervous system. Both DDAH1 and 2 are expressed in the developing limb buds in patterns overlapping areas with high nitric oxide synthase activity. These expression patterns implicate DDAH1 and DDAH2 in embryonic development, possibly through specific effects on nitric oxide pathways.
\end{abstract}

KEY WORDS: DDAH, nitric oxide, embryonic development, mouse, transgenic

\section{Introduction}

Dimethylarginine Dimethylaminohydrolase (DDAH) modulates nitric oxide signalling by catalysing the hydrolysis of asymmetric dimethylarginine (ADMA), an endogenous inhibitor of all three isoforms of nitric oxide synthase (Leiper, 2005). It is, however, becoming apparent that DDAH may also have roles independent of nitric oxide signalling, perhaps through association NF1 (Tokuo et al., 2001) or Sp1 (Hasegawa et al., 2006).

In mammals, there are two isoforms of DDAH, expressed in most human and murine fetal tissues (Tran et al., 2000; Tran et al., 2003). The role of DDAH in development is largely unknown, but rat DDAH1 RNA has been shown to be developmentally regulated (Mishima et al., 2004). Nitric oxide is generated at high levels during implantation of the blastula (Saxena et al., 2000). Angiogenesis and vasodilatation in the developing placenta are also postulated to be nitric oxide dependent (Lyall, 2003). Embryonic implantation and development of the placental vasculature are disrupted by experimental manipulation of nitric oxide levels (Lyall, 2003). Despite these observations, deletion of all three nitric oxide synthase isoforms does not appear to have a major impact on fetal development (Morishita et al., 2005).

The aim of the present study was to determine whether DDAH is important in normal fetal development. We have generated null alleles for mouse DDAH1 and 2. Here we report that heterozygote DDAH $1^{\text {wt/del }}$ embryos and pups are macroscopically indistinguishable from wild-type embryos while adult mice exhibit endothelial dysfunction and pulmonary hypertension (Leiper et al., 2007). Early homozygous DDAH1 $1^{\text {del/del }}$ embryos are generated at very low frequencies, and fail to progress through early embryonic development. DDAH1 protein is expressed in the embryonic trophoblast, but not in the early embryo. In contrast, DDAH2 null

Abbreviations used in this paper: ADMA, asymmetric dimethylarginine; DDAH, dimethylarginine dimethylaminohydrolase; NO, nitric oxide.

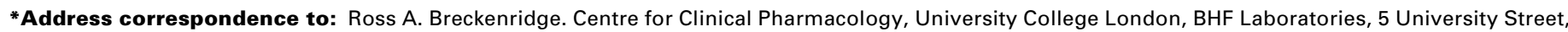
London WC1E 6JJ, UK. Fax: +44-208-816-2009. e-mail: rbrecke@nimr.mrc.ac.uk
}

\#Current Address: GlaxoSmithKline Research and Development, Greenford Road, Greenford, Middlesex UB6 OHE, UK 
mice exhibit are viable and fertile apparently with no abnormal phenotype. DDAH1 and DDAH2 RNA are expressed in dynamic, overlapping but distinct patterns throughout embryonic development, partially overlapping with NF1 RNA expression. We hypothesise that DDAH plays a role in embryonic development, which may in part be nitric oxide dependent.

\section{Results}

\section{Heterozygote DDAH1(wt/del) embryos are morphologically in- distinguishable from wild-type embryos}

Heterozygous DDAH1 ${ }^{\text {(wt/del) }}$ embryos express DDAH1 RNA and protein at approximately $50 \%$ of wild-type levels, while circulating plasma ADMA levels of heterozygotes are $\sim 20 \%$ higher than those of wild-type mice. Heterozygotes are morphologically indistinguishable from wild-type littermates. This has been reported in detail elsewhere (Leiper et al., 2007).

\section{Homozygote DDAH2 ${ }^{(\mathrm{del} / \mathrm{del})}$ mice exhibit normal development and survival}

We have also generated mice carrying an inactivated DDAH2 locus. These mice have reduced DDAH2 expression at both the
RNA and protein levels (not shown) in all tissues studied. Breeding of these mice indicates that both heterozygous and homozygous inactivation of the DDAH2 locus does not impact on embryonic survival, with wild type, heterozygous and null mice produced in Mendelian ratios. 21 litters were collected from heterozygote DDAH2 ${ }^{\text {(wt/del) }}$ parents, 176 mice in all. $41(23.3 \%)$ were found to

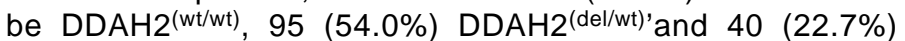
$\mathrm{DDAH} 2^{(\mathrm{del} / \mathrm{del})}$. A detailed characterisation of these mice will be presented elsewhere.

\section{Reduction of DDAH1 expression levels affects early embry- onic development at several points}

Thirty-four DDAH1 $1^{\text {(wt/del)/ DDAH1 }}$ (wt/del) $^{\text {crosses were carried }}$ out. We observed that approximately $33 \%$ of the resulting pups were wild-type DDAH $1^{\text {(wt/wt) }}$ and $66 \%$ heterozygote DDAH $1^{\text {(wt/del) }}$ (72 vs. 166, 238 pups scored). Genotyping of embryonic day 2

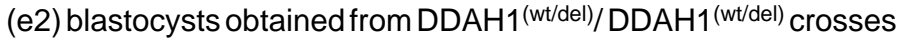
indicated that homozygous embryos were present, albeit at low frequency $\sim 5 \%$ ( 4 out of 79 scored). See Fig. 1 for representative genotyping results.

We observed significant numbers of resorbing embryos at e15

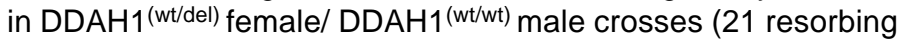
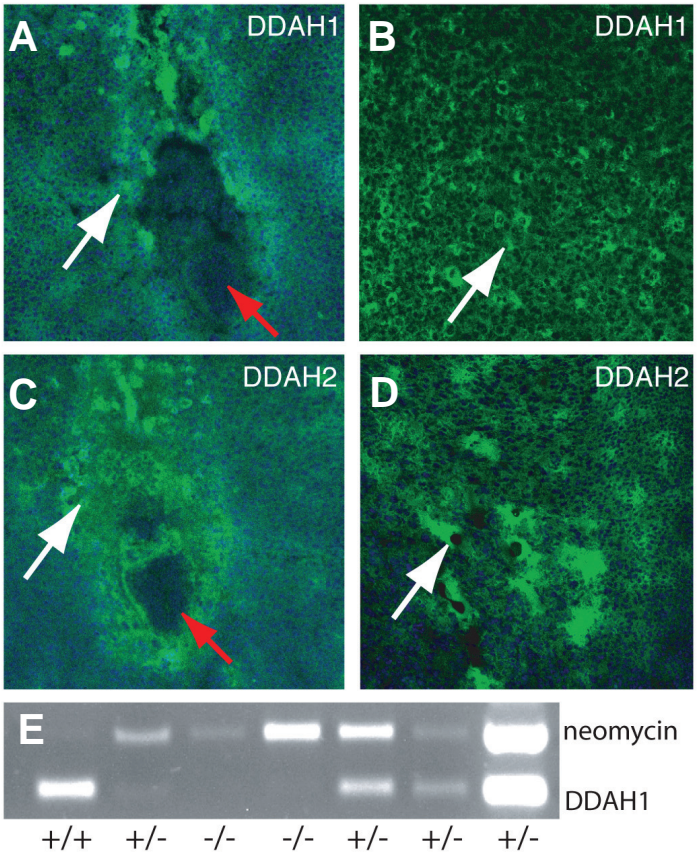
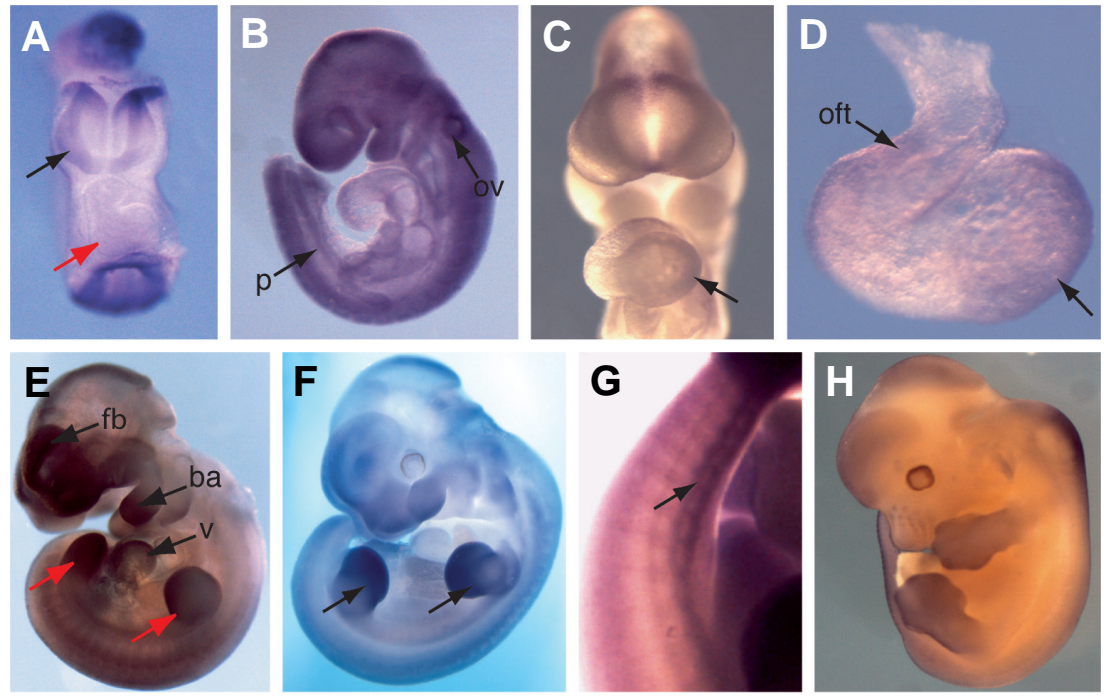

Fig. 1 (Left). Immunohistochemistry of 6-day pregnant mouse cryostat sectioned uterus with polyclonal anti-DDAH serum. (A) Immunofluorescence of cryosectioned e6.5 embryo and placenta for DDAH1 (green), showing anti-DDAH1 activity in the trophoblast (white arrow), with absent activity in the implanted embryo (red arrow) (blue stain is nuclear DAPI). (C) Anti-DDAH2 immunofluorescence in e6.5 embryo and uterus (white arrow) showing higher levels of anti DDAH2 activity surrounding the embryo (embryo marked by red arrow). Note higher levels of embryonic DDAH2 than DDAH1 in (A). (B) Anti-DDAH1 immunofluorescence throughout the 6.5-day pregnant mouse placenta (arrowed), in contrast to anti$D D A H 2$ immunofluorescence activity, which is associated with developing blood vessels (D, arrowed). (E) Representative agarose gel of blastocyst genotyping by PCR of Neomycin and DDAH-1 amplicons. Blastocycts collected at day 2-post fertilization from a heterozygous DDAH-1 null female crossed to a heterozygous null DDAH-1 male. Genotypes indicated are "+/"= DDAH-1 heterozygous null, "+/+"= wild-type, "-/-"= DDAH-1 homozygous null.

Fig. 2 (Right). In situ hybridisation to DDAH1 antisense RNA, revealing expression pattern of DDAH1 RNA during embryonic development. (A) e8.5 embryo, showing strong DDAH1 RNA expression in the neural folds (black arrow) but not the heart (red arrow). (B) Widespread DDAH1 RNA expression in e9.5 embryo (ov-otic vesicle, p-pronephros) (C) Anterior view of e9.5 embryo, showing DDAH1 in situ hybridisation staining in the ventricle (arrowed). (D) Dissected e9.5 heart, showing DDAH1 RNA expression in the ventricle (arrowed) and outflow tract (oft). (E) e10.5 embryo, showing DDAH1 RNA expression in the fore-brain (fb), cardiac ventricle (v), branchial arches (ba) and limb bud (red arrows). (F) Strong expression of DDAH1 RNA is seen in the limb of e12.5 embryo (arrowed). (G) High-power view of tail vasculature (arrowed) of e12.5 embryo. (H) e14.5 embryo, showing DDAH1 RNA staining in the vibrissae, brain and limbs. 

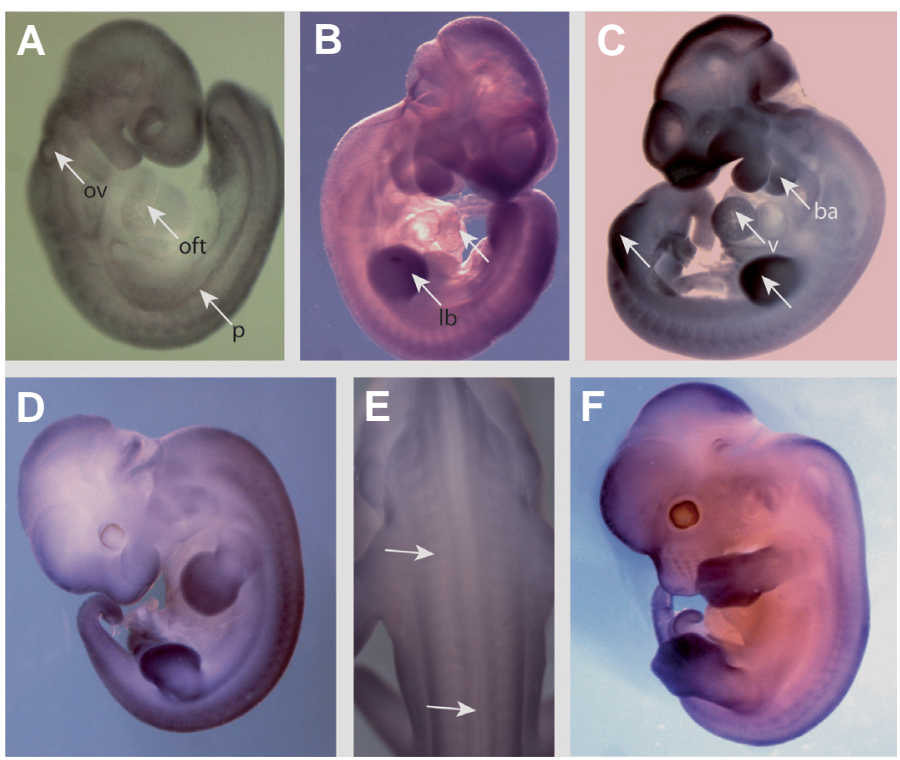

Fig. 3. In situ hybridisation to DDAH2 antisense RNA, revealing expression pattern of DDAH2 RNA during embryonic development. (A) Expression of DDAH2 in e9.5 embryo, visible in the otic vesicle (ov), cardiac outflow tract (oft) and pronephros (p). (B,C) e10.5 embryo revealing expression in the limb buds (arrowed), branchial arches (ba), cardiac ventricle (v). (D,E) expression in e12.5 embryo, revealing strong limb bud expression, and peripheral nervous system staining larrowed in the dorsal view of the embryo in E). In e14.5 embryo (F) expression is seen in the limbs, and peripheral nervous system.

embryos out of a total of 73 embryos, 28.8\%). In contrast, resorbing embryos were rare in DDAH $1^{\left.{ }^{(w t} / \mathrm{wt}\right)}$ female/ $\mathrm{DDAH} 1^{\text {(wt/ }}$ del) male crosses (2 out of $42,4.8 \%$ ). The ratio of wild-type to heterozygote DDAH1 $1^{\text {(wt/del) }}$ pups was approximately $1: 1$ in both of these crosses however litters from $\mathrm{DDAH}_{1}{ }^{\text {(wt/del) }}$ female/ $\mathrm{DDAH} 1^{(\mathrm{wt} / \mathrm{wt})}$ male crosses were significantly smaller than from $\mathrm{DDAH}_{1}{ }^{\left.{ }^{\mathrm{wt}} / \mathrm{wt}\right)}$ female/ DDAH1 ${ }^{(\mathrm{wt} / \mathrm{del})}$ male crosses $(6.53 \pm 0.6 \mathrm{vs}$. $10.42 \pm 0.7, p \leq 0.001 \mathrm{n}=19)$. This implies a role for DDAH1 in utero-placental function. No overall subfertility was observed in either male or female DDAH1 $1^{\left.{ }^{(w t / d e l}\right)}$ heterozygotes.

Immunohistochemistry of cryostat sectioned uteri from wildtype 6.5-day pregnant female (CBA/B/10) mice using rabbit anti-mouse DDAH1 polyclonal serum revealed that DDAH1 is present in the trophoblast, but not the embryo itself (Fig. 1A). Expression of DDAH1 was evident throughout the uterus (Fig. 1B). Immunohistochemistry with anti$\mathrm{DDAH} 2$ polyclonal serum revealed that DDAH2 protein is also present in the trophoblast (Fig. $1 \mathrm{C})$, and is additionally associated with the developing placental vasculature (Fig. 1D).

\section{DDAH isoforms are expressed in a dynamic, overlapping pattern during embryonic de- velopment}

RNA in situ analysis of wild-type embryos with digoxigenin-labelled RNA antisense probes for DDAH1 and DDAH2 was carried out. DDAH1 RNA expression was observed in the developing forebrain of the e8.5 embryo, with weak expression visible in the heart (Fig. 2A). Cardiac expression of DDAH1 RNA was seen in the outer curvature of the cardiac ventricle and cardiac outflow tract at e9.5 (Fig. 2 C,D). Expression is visible in the forebrain, branchial arches and cardiac ventricle at e10.5 (Fig. 1E). At e12.5, the dorsal aortas and tail blood vessels were stained for DDAH1 RNA (Fig. 2 F,G). Strikingly, DDAH1 RNA expression was seen in the developing limb buds from e10.5 onwards (Fig. $2 \mathrm{E}, \mathrm{F}, \mathrm{H}$ ), concentrated in the distal regions of the limb at e12.5 (Fig. 2F), less pronounced by e14.5 (Fig. 2H)

In situ hybridisation of wild-type mouse embryos to digoxigenin-labelled DDAH2 antisense RNA probes revealed that DDAH2 RNA expression was present in the cardiac outflow tract, otic vesicle and pronephros at e9.5 (Fig. 3A). Expression in the left ventricle and cardiac outflow tract, branchial arches and limb buds was observed at e10.5 (Fig. 3 B,C). At e12.5, DDAH2 RNA expression was detected in the limb buds and peripheral nervous system (Fig. 3 D,E). This pattern was also visible at e14.5, albeit weakly (Fig. 3F).

Expression of NF1, a RASGTPase activating factor shown to coimmunoprecipitate with rat DDAH1 in vitro (Tokuo et al., 2001), was also investigated. In situ hybridisation to a digoxigenin-labelled antisense NF1 RNA probe revealed overlapping expression with the two DDAH isoforms. At e9.5, NF1 was expressed in the branchial arches, early limb bud and otic placode (Fig. 4A). At e12.5, NF1 RNA was detectable in the limb bud and developing brain (Fig. 4 B,C), overlapping with DDAH1 and 2 RNA expression (Figs. 2 and 3 ).

\section{NADPH diaphorase staining overlaps DDAH RNA expres- sion patterns}

NADPH-diaphorase staining relies on the fact that nitric oxide synthase isoforms are NADPH-diaphorases, and will thus hydrolyse nitro-blue-di-tetrazolium in the presence of NADPH, giving a chromogenic reaction (Weinberg et al., 1996). NADPH-diaphorase staining of e9.5 embryos revealed nitric oxide synthase activity throughout the heart, and in the limbbud, pronephros, branchial arches, otic placode and forebrain (Figs. 5 A,D). At e10.5 diaphorase staining was observed in the cardiac ventricle and outflow tract, limb bud, somites, branchial arches and brain (Fig. 5 B,E). By e11.5, strong staining was
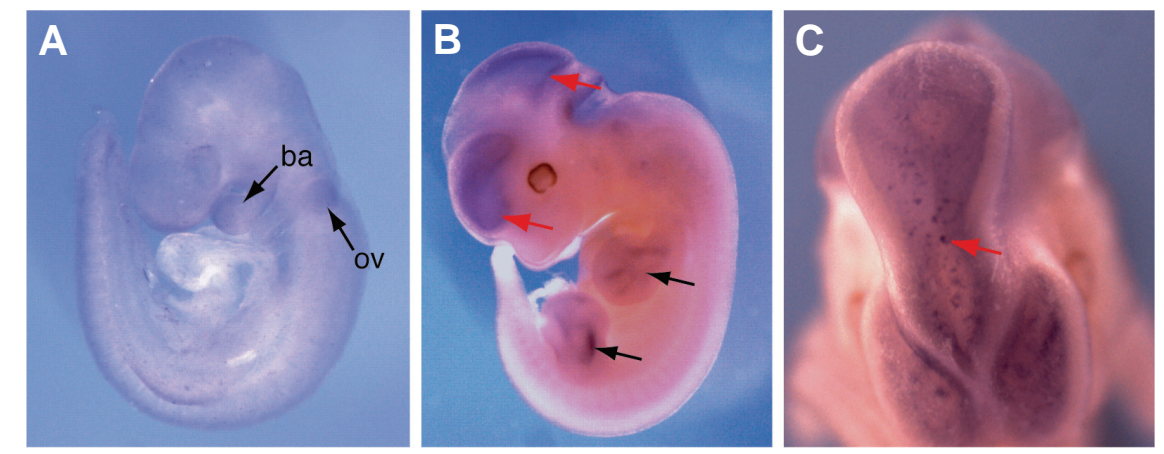

Fig. 4. Developmental expression profile of the RASGTPase NF1 overlaps with DDAH1 and 2. At e9.5 (A), expression of NF1 RNA is evident in the otic vesicle (ov) and branchial arches (ba). (B,C) At e12.5, expression is seen in the limb buds (black arrows in B) and brain (red arrows in $B, C$ ). 

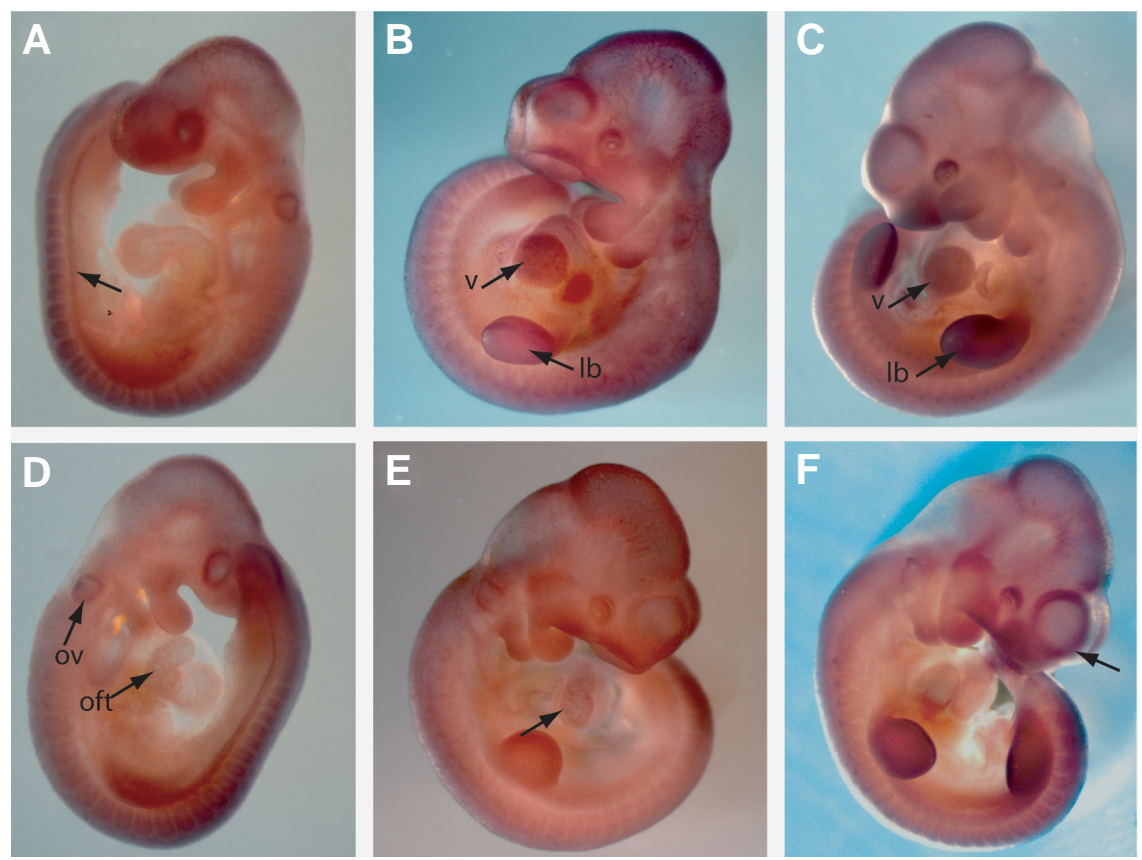

Fig. 5. NADPH diaphorase staining pattern of embryos, revealing nitric oxide synthase activity at $\mathbf{e 9 . 5}(\mathbf{A}, \mathbf{D}), \mathbf{e} \mathbf{1 0 . 5}(\mathbf{B}, \mathbf{E})$ and $\mathbf{e} \mathbf{1 2 . 5}(\mathbf{C}, \mathbf{F})$. Strong diaphorase activity is seen at e9.5 in the pronephros (A, arrowed), cardiac outflow tract ( $D$, oft) and otic vesicle ( $D$, ov). (B) Limb diaphorase activity is seen at e 10.5 (Ib), and staining is evident in the cardiac ventricle ( $\mathrm{V}$ ) and cardiac outflow tract (E, arrowed). At e12.5, strong activity is evident in the limb buds (C, Ib), as well as cardiac ventricle $(C, v)$ and forebrain $(E$, arrowed).

observed in the developing limbs, left ventricle and forebrain (Fig. 5 C,F).

\section{Discussion}

In this study we report that DDAH1 null mouse embryos are generated at low efficiency, and fail to complete embryonic development. Embryonic DDAH1 and DDAH2 RNA expression patterns are dynamic and overlapping but distinct, with DDAH1 RNA expression detectable in the developing vasculature, and DDAH2 RNA in the embryonic peripheral nervous system. Nitric oxide synthase activity overlaps DDAH1 and 2 RNA expression. Interestingly, expression of NF-1 RNA, which encodes a protein reported to coimmunoprecipitate with DDAH1 in rat, overlaps in the developing limb and brain, consistent with a potential interaction of NF1 and DDAH in development.

Circumstantial evidence supports a role for nitric oxide in blastocyst implantation, in that nitric oxide synthase isoforms are expressed at high levels in the trophoblast (Gouge et al., 1998; Purcell et al., 1999; Gagioti et al., 2000; Saxena et al., 2000). Nitric oxide has been postulated to have several roles in embryonic implantation and placentation, for example as a phagocytic toxin in trophoblast giant cells (Gagioti et al., 2000) and an angiogenic signal in the developing placenta (Cooke and Losordo, 2002; Lyall, 2003). Administration of inhibitors of nitric oxide synthesis to in vitro assays of implantation and trophoblast outgrowth suggest that nitric oxide synthesis is tightly regulated during implantation (Sengoku et al., 2001). eNOS/iNOS double knockout mice produce fewer homozygous double null mice than expected, consistent with an implantation defect (Tranguch and
Huet-Hudson, 2003). The triple eNOS/iNOS/nNOS null mouse has reduced fertility, but interestingly some triple null embryos are viable (Morishita et al., 2005). Thus the fertilisation and implantation defect we observe in DDAH1 null blastocysts could be nitric oxide dependent, with a greater magnitude than predicted but the survival of the triple NOS knockout mouse seems to argue against this.

We found that DDAH1-null pre-implantation embryos are produced at very low frequency (5\%) indicating that DDAH protein and/or activity is involved in fertilisation or the earliest stages of embryogenesis. The ratio of heterozygote to wildtype DDAH1 pre-implantation embryos was similar to that of viable pups, suggesting that heterozygous deletion of DDAH in the embryo does not have any effect on embryonic viability. However, we did observe significant embryonic resorption in

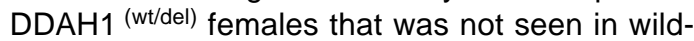
type females. This observation suggests that elevated maternal ADMA (raised in DDAH1 (wt/del) $^{\text {(t) }}$ heterozygotes (Leiper et al., 2007)) may negatively impact embryonic viability post-implantation. Consistent with this suggestion, elevated plasma ADMA levels have been reported in human pre-eclampsia (Savvidou et al., 2003) and intrauterine growth retardation (Rutherford et al., 1995).

Even though DDAH1 and DDAH2 protein expression patterns in the placenta overlap (Fig. 1), we observed no implantation of $\mathrm{DDAH} 1^{\text {(del/del) }}$ blastocysts and no detectable phenotype in DDAH2 $2^{\text {(del/del) }}$ embryos and mice, implying no functional redundancy in the trophoblast between DDAH1 and DDAH2. However, the normal development of DDAH2 $2^{\text {(del/del) }}$ mice suggests that DDAH1 can compensate of the loss of DDAH2.

Expression patterns of DDAH1 and 2 RNA suggest roles in several developing organ systems. It has previously been shown at that all-trans retinoic acid, which has multiple roles in cardiac and neural development induces DDAH2 in vitro (Achan et al., 2002). We observe DDAH2 RNA expression in the developing heart and neural systems (Fig. 3). A role for nitric oxide signalling in neurogenesis has been suggested in Xenopus laevis, drosophila and chick (Peunova and Enikolopov, 1995; Kuzin et al., 1996; Peunova et al., 2001; Plachta et al., 2003). We observe expression of DDAH1 and 2 in the developing brains of mouse embryos in patterns overlapping NF1 RNA expression. Interestingly, these molecules continue to be expressed in overlapping patterns in the adult mouse brain (www.brainatlas.org/ala/). Use of inducible, organ specific Cre lines in conjunction with conditional alleles of DDAH isoforms and NF1, and generation of double conditional DDAH1 and 2 null mutants will allow investigation of potential nitric oxide independent functions of DDAH isoforms in brain development and function.

Unexpectedly, expression of both DDAH isoforms was observed in the developing limb (Figs. 2, 3). Furthermore, we observed localisation of nitric oxide synthase RNA and nitric oxide synthase activity in the limb buds at several developmental stages (Figs. 5, 6). Administration of the nitric oxide synthesis inhibitor I- 
NAME to pregnant rats has been reported to cause a haemorrhagic fetal limb phenotype (Fantel et al., 1999), and sporadic limb loss in eNOS null mice has been reported (Gregg et al., 1998), suggesting that nitric oxide signalling functions in limb development. We observed an overlapping distribution of expression of both DDAH isoforms in the limb with RNA encoding the RASGTPAse activating factor NF1, shown to coimmunoprecipitate with DDAH1 in the rat (Tokuo et al., 2001). At the moment, the functional significance in vivo of the association between NF1 and DDAH1 is unknown, as is whether this is related functionally to nitric oxide or RAS signalling. In the context of the developing limb and brain in our study, there is evidence of nitric oxide synthase activity from NADPH-diaphorase staining overlapping DDAH1/2 and nitric oxide synthase isoform RNA expression domains.

The co-localisation we observed of nitric oxide synthase and DDAH isoform RNA with nitric oxide synthase activity is circumstantial evidence for a nitric oxide synthase-dependent role of DDAH1 and 2 during development. However, the (albeit poor) survival and seemingly normal gross phenotype of the triple eNOS/iNOS/nNOS null transgenic mouse challenges the hypothesis that nitric oxide signalling is an essential developmental regulator in the mouse. The triple nitric oxide synthase mouse reportedly exhibits low levels of fertility but grossly normal morphology, albeit with the development of diabetes insipidus, and poor survival (Morishita et al., 2005). It is not known whether nitric oxide itself is absent in these embryos and mice. The low level of generation and subsequent failure to develop of DDAH1 null embryos in our study therefore suggests a nitric-oxide independent role for DDAH in fertilisation and early embryonic development. The previous reports of association of DDAH isoforms with NF1 and Sp1 suggests mechanisms of nitric oxide-independent activity for the DDAH isoforms, regulating these respective signalling pathways. Obviously there may be more dimerisation partners for $\mathrm{DDAH}$, and a potential role for $\mathrm{DDAH}$ proteins as transcriptional modifiers is currently under investigation in our laboratory. Generation of conditional double null DDAH1 and 2 mice will address the issue of the importance of these nitric oxide independent actions in normal development, and redundancy of DDAH isoforms suggested by the survival of our DDAH2 null mice. The survival of the triple eNOS/iNOS/nNOS null mouse obviously raises fundamental questions about the role of nitric oxide in mammalian development. Further reports of the phenotype of the triple eNOS/iNOS/nNOS null are awaited.

Our results demonstrate a role for DDAH1 in early mouse development and suggest involvement of DDAH1 and 2 in development of several organ systems. The reported normal development of the triple eNOS/iNOS/nNOS null mouse suggests that any role of DDAH in development may be nitric oxide independent. We are currently generating mice bearing conditional null alleles for both DDAH isoforms. In conjunction with tissue-specific Cre lines, this will allow detailed investigation of the roles of DDAH isoforms in organ development.

\section{Materials and Methods}

Generation of mouse lines: generation of DDAH1 null mouse is described in Leiper et al., Nature Medicine 2007. We have disrupted exon 3 of the DDAH2 gene. This exon contains the initiating ATG and encodes the N-terminal 100 amino acids of the protein. Disruption of exon 3 generates a null allele that is unable to express functional protein (as confirmed by western blotting). A full description of this transgenic line will be given elsewhere (manuscript in preparation).

\section{DNA extraction and genotyping of DDAH-1 genetically modified animals}

At time of weaning, tail sections were taken from animals for genotyping. Genomic DNA was prepared using DNAeasy Kit (Qiagen) following the manufacturer's instructions. Primers used were

DDAH-1 exon forward (5'- CGAGCCACCGACTCAAAC -3'),

DDAH-1 exon 1 reverse (5'-GAGCGAAATCCACCTCCTC-3'), and

Neomycin reverse (5'-GCTTGGCTGGACGTAAACTC-3')

(all from Sigma-Genosys). DDAH-1 forward and DDAH-1 reverse amplified a 175 base pair fragment indicating the wild-type DDAH-1 gene while DDAH- 1 forward and Neomycin reverse amplified a fragment of 290 base pairs indicating the presence of the DDAH-1 knockout. For PCR amplification, $26 \mu \mathrm{L}$ of $1.1 \times$ Reddy-Mix (VWR) was combined with $200 \mu \mathrm{mol}$ of each of the three primers and $2 \mu \mathrm{g}$ of genomic DNA. Thermal cycling conditions were $95 \mathrm{C}$ for 3 minutes, followed by 40 cycles of $95^{\circ} \mathrm{C}$ for 20 seconds, $60^{\circ} \mathrm{C}$ for 40 seconds, and $72^{\circ} \mathrm{C}$ for 1 minute, and finally $72^{\circ} \mathrm{C}$ for 5 minutes. PCR products were run on a $2 \%$ agarose gel, stained with ethidium bromide, and visualized using a UV illuminator and GeneSnap software (Syngene). Genotypes were scored by presence or absence of bands for DDAH-1 or Neomycin.

\section{Isolation of blastocysts, and scoring of resorbing embryos}

Placing two female mice into the cage of a male performed trio mating. Timed mating was performed by checking for the presence of a vaginal plug in the morning shortly after the end of the dark phase of the animal facilities light cycle. For blastocyst isolation, on the third day following vaginal plug presence, females were sacrificed by cervical dislocation. The oviducts and uterus were removed and gently rinsed with sterile PBS to flush out pre-implanted blastocysts. Isolated blastocysts were rinsed in sterile PBS to remove maternal contamination. To isolate genomic DNA, blastocysts was placed in lysis buffer $(50 \mathrm{mM}$ Tris- $\mathrm{HCl} \mathrm{pH} 8-8.5,1 \mathrm{mM}$ EDTA, and $0.5 \%$ Tween-20) and $2 \mu \mathrm{L}$ of $2 \mathrm{mg} / \mathrm{ml}$ Proteinase $\mathrm{K}$ (SigmaAldrich) for 5 hours at $55^{\circ} \mathrm{C}$ followed by $95^{\circ} \mathrm{C}$ for 5 minutes and then stored at $-20^{\circ} \mathrm{C}$

For resorption studies, following the identification of the vaginal plug, pregnant females were phenotypically screened for abdominal distension at 12-14 days of gestation to confirm pregnancy. At day e15, pregnant females were sacrificed using cervical dislocation and embryos were dissected to score phenotypes. Embryos were sacrificed by approved procedures. Following sacrifice, tail sections of all animals used for blastocyst and resorption studies were taken and post mortem genotyping was performed to confirm genotype.

\section{Immunohistochemistry on cryostat sections}

This was carried out as previously described (Leu et al., 2001).

\section{In situ hybridisation}

This was carried out essentially as previously described (Riddle et al., 1993). All cDNAs were cloned unidirectionally into the vector pSport6 from the relevant IMAGE clone; DDAH1 (accession number BQ963666), DDAH2 (BQ899468), eNOS(CB181220), nNOS(CF744713), iNOS (BG974882). Plasmids were linearised, and antisense RNA labelled with digoxigenin-UTP (Boehringer Ingelheim) was prepared.

Diaphorase staining was carried out as previously described (Weinberg et al., 1996).

\section{References}

ACHAN V, TRAN C.T., ARRIGONI F, WHITLEY G.S., LEIPER J.M. and VALLANCE P. (2002). all-trans-Retinoic acid increases nitric oxide synthesis by endothelial cells: a role for the induction of dimethylarginine dimethylaminohydrolase. Circ Res 90: 764-769. 
COOKE J.P. and LOSORDO D.W. (2002). Nitric oxide and angiogenesis. Circulation 105:2133-2135.

FANTEL A.G., STAMPS L.D., TRAN T.T., MACKLER B., PERSON R.E. and NEKAHI N. (1999). Role of free radicals in the limb teratogenicity of L-NAME (N(G)-nitro-(L)-arginine methyl ester): a new mechanistic model of vascular disruption. Teratology 60: 151-160.

GAGIOTI S., SCAVONE C. and BEVILACQUA E. (2000). Participation of the mouse implanting trophoblast in nitric oxide production during pregnancy. Biol Reprod 62: 260-268.

GOUGE R.C., MARSHBURN P., GORDON B.E., NUNLEY W. and HUET-HUDSON Y.M. (1998). Nitric oxide as a regulator of embryonic development. Biol Reprod 58: 875-879.

GREGG A.R., SCHAUER A., SHI O., LIU Z., LEE C.G. and O'BRIEN W.E. (1998). Limb reduction defects in endothelial nitric oxide synthase-deficient mice. Am J Physiol 275: H2319-H2324.

HASEGAWA K., WAKINO S., TANAKA T., KIMOTO M., TATEMATSU S., KANDA T., YOSHIOKA K., HOMMA K., SUGANO N., KURABAYASHI M., SARUTA T. and HAYASHI K. (2006). Dimethylarginine Diaminohydrolase 2 Increases Vascular Endothelial Growth Factor Expression Through Sp1 Transcription Factor in Endothelial Cells. Arterioscler Thromb Vasc Biol 26: 1488-1494.

KUZIN B., ROBERTS I., PEUNOVA N. and ENIKOLOPOV G. (1996). Nitric oxide regulates cell proliferation during Drosophila development. Cell 87: 639-649.

LEIPER J., NANDI M., TORONDEL B., MURRAY-RUST J., MALAKI M., O'HARA B., ROSSITER S., ANTHONY S., MADHANI M., SELWOOD D., SMITH C., WOJCIAK-STOTHARD B., RUDIGER A., STIDWILL R., MCDONALD N.Q. and VALLANCE P. (2007). Disruption of methylarginine metabolism impairs vascular homeostasis. Nat Med 13: 198-203.

LEIPER J.M. (2005). The DDAH-ADMA-NOS pathway. Ther Drug Monit 27: 744746.

LEU M., EHLER E. and PERRIARD J.C. (2001). Characterisation of postnatal growth of the murine heart. Anat Embryol (Berl) 204: 217-224.

LYALL F. (2003). Development of the utero-placental circulation: the role of carbon monoxide and nitric oxide in trophoblast invasion and spiral artery transformation. Microsc Res Tech 60: 402-411.

MISHIMA T., HAMADA T., UI-TEI K., TAKAHASHI F., MIYATA Y., IMAKI J., SUZUKI H. and YAMASHITA K. (2004). Expression of DDAH1 in chick and rat embryos. Brain Res Dev Brain Res 148: 223-232.

MORISHITA T., TSUTSUI M., SHIMOKAWA H., SABANAI K., TASAKI H., SUDA O., NAKATA S., TANIMOTO A., WANG K.Y., UETA Y., SASAGURI Y., NAKASHIMA Y. and YANAGIHARA N. (2005). Nephrogenic diabetes insipidus in mice lacking all nitric oxide synthase isoforms. Proc Natl Acad Sci USA 102: 10616-10621.

PEUNOVA N. and ENIKOLOPOV G. (1995). Nitric oxide triggers a switch to growth arrest during differentiation of neuronal cells. Nature 375: 68-73.

PEUNOVA N., SCHEINKER V., CLINE H. and ENIKOLOPOV G. (2001). Nitric oxide is an essential negative regulator of cell proliferation in Xenopus brain. $J$ Neurosci 21: 8809-8818.

PLACHTA N., TRAISTER A. and WEIL M. (2003). Nitric oxide is involved in establishing the balance between cell cycle progression and cell death in the developing neural tube. Exp Cell Res 288: 354-362.

PURCELL T.L., GIVEN R., CHWALISZ K. and GARFIELD R.E. (1999). Nitric oxide synthase distribution during implantation in the mouse. Mol Hum Reprod5: 467475 .

RIDDLE R.D., JOHNSON R.L., LAUFER E. and TABIN C. (1993). Sonic hedgehog mediates the polarizing activity of the ZPA. Cell 75: 1401-1416.

RUTHERFORD R.A., MCCARTHY A., SULLIVAN M.H., ELDER M.G., POLAK J.M. and WHARTON J. (1995). Nitric oxide synthase in human placenta and umbilical cord from normal, intrauterine growth-retarded and pre-eclamptic pregnancies. Br J Pharmacol 116: 3099-3109.

SAVVIDOU M.D., HINGORANI A.D., TSIKAS D., FROLICH J.C., VALLANCE P. and NICOLAIDES K.H. (2003). Endothelial dysfunction and raised plasma concentrations of asymmetric dimethylarginine in pregnant women who subsequently develop pre-eclampsia. Lancet 361: 1511-1517.

SAXENA D., PUROHIT S.B., KUMER G.P. and LALORAYA M. (2000). Increased appearance of inducible nitric oxide synthase in the uterus and embryo at implantation. Nitric Oxide 4: 384-391.

SENGOKUK., TAKUMA N., HORIKAWAM., TSUCHIYAK., KOMORIH., SHARIFA D., TAMATE K. and ISHIKAWA M. (2001). Requirement of nitric oxide for murine oocyte maturation, embryo development, and trophoblast outgrowth in vitro. Mol Reprod Dev 58: 262-268.

TOKUO H., YUNOUE S., FENG L., KIMOTO M., TSUJI H., ONO T., SAYA H. and ARAKI N. (2001). Phosphorylation of neurofibromin by cAMP-dependent protein kinase is regulated via a cellular association of $N(G), N(G)$-dimethylarginine dimethylaminohydrolase. FEBS Lett 494: 48-53.

TRAN C.T., FOX M.F., VALLANCE P. and LEIPER J.M. (2000). Chromosomal localization, gene structure, and expression pattern of DDAH1: comparison with DDAH2 and implications for evolutionary origins. Genomics 68: 101-105.

TRAN C.T., LEIPER J.M. and VALLANCE P. (2003). The DDAH/ADMA/NOS pathway. Atheroscler Suppl 4:33-40.

TRANGUCH S. and HUET-HUDSON Y. (2003). Decreased viability of nitric oxide synthase double knockout mice. Mol Reprod Dev 65: 175-179.

WEINBERG R.J., VALTSCHANOFF J.G. and SCHMIDT H.H.H.W. (1996). Methods in Nitric Oxide Research. In Methods in Nitric Oxide Research (Ed. Feelisch M., Stammler J.S.). Wiley, London, pp 237-248. 


\section{Further Related Reading, published previously in the Int. J. Dev. Biol.}

See our recent Special Issue Fertilization, in honor of David L. Garbers and edited by Paul M. Wassarman and Victor D. Vacquier at: http://www.ijdb.ehu.es/web/contents.php?vol=52\&issue=5-6

Mobilisation of stored calcium in the neck region of human sperm - a mechanism for regulation of flagellar activity

Kweku Bedu-Addo, Sarah Costello, Claire Harper, Gisela Machado-Oliveira, Linda Lefievre, Christopher Ford, Christopher Barratt and Stephen Publicover

Int. J. Dev. Biol. (2008) 52: 615-626

TBX1, a DiGeorge syndrome candidate gene, is inhibited by retinoic acid Lifeng Zhang, Tao Zhong, Yuexiang Wang, Qiu Jiang, Houyan Song and Yonghao Gui Int. J. Dev. Biol. (2006) 50: 55-61

Development and pathology of the hyaloid, choroidal and retinal vasculature Magali Saint-Geniez and Patricia A. D'Amore

Int. J. Dev. Biol. (2004) 48: 1045-1058

Efficient Cre-mediated deletion in cardiac progenitor cells conferred by a 3'UTR-iresCre allele of the homeobox gene Nkx2-5

Edouard G Stanley, Christine Biben, Andrew Elefanty, Louise Barnett, Frank Koentgen, Lorraine Robb and Richard P Harvey

Int. J. Dev. Biol. (2002) 46: 431-439

The contribution of the proepicardium to avian cardiovascular development JM Perez-Pomares, A Phelps, R Munoz-Chapuli, A Wessels

Int. J. Dev. Biol. (2001) 45: S155-S156

Embryonic and larval development of NADPH-diaphorase/nitric oxide synthase reactivity in the brain of the amphibian Pleurodeles walt

N Moreno, JM Lopez, C Sanchez-Camacho, M Crespo, M Munoz, A Gonzalez Int. J. Dev. Biol. (2001) 45: S81-S82

Histochemical detection of nitric oxide synthase during the development of murine lung $L$ Guembe, A C Villaro and M E Bodegas

Int. J. Dev. Biol. (1996) 40: S255-S256 